RECyT

Año 23 / № 35 / 2021 / 66-72

\title{
Estimación del costo hospitalario de las úlceras crónicas de miembros inferiores en Tucumán, Argentina
}

\section{Estimating hospital cost of chronic lower limb ulcers in Tucumán, Argentina}

\author{
Romina Chavez-Jara*, Nicolás Cerusico, María Lazarte, \\ Carla A. Cabrera, María E. Sesto Cabral, Alberto N. Ramos
}

\begin{abstract}
Laboratorio de Estudios Farmacéuticos y Biotecnología Farmacéutica (LEFyBiFa), Instituto de Biotecnología Farmacéutica y Alimentaria (INBIOFAL), CONICET-Universidad Nacional de Tucumán. Av. Roca 2000. San Miguel de Tucumán (T4000). Argentina.

*E-mail: romachavez@gmail.com

Recibido: 21/02/2019; Aprobado 07/09/2020
\end{abstract}

\section{Resumen}

\begin{abstract}
Antecedentes: Las úlceras crónicas de miembros inferiores (UCMI) representan un gran problema para los pacientes y los sistemas de salud.

Objetivo: Determinar el número y el costo de consultas e internaciones asociadas a las UCMI en un hospital público en Tucumán, Argentina.

Métodos: Estudio retrospectivo observacional. La estimación del costo se calculó basada en los días de internación, número de consultas, tratamientos realizados y análisis de laboratorio.

Resultados: En el periodo 2013-2014, se identificaron 7224 consultas y 359 internados con códigos CIE-10 relacionados a UCMI.

La estancia media fue de 22.88 días. Se observó una media de 0.41 cirugías por pacientes, donde el 25\% fueron amputaciones. El costo anual asociado al tratamiento de UCMI en pacientes internados fue US\$ 4.053,65, mientras que en pacientes ambulatorios fue US\$ 3.589,24.

Conclusión: Las UCMI generan una gran carga económica para el Sistema de Salud público en Argentina. Por tanto, es necesario un cambio en la forma de registro de las UCMI en los hospitales, que permita al Sistema de Salud público tomar conciencia del problema y generar las políticas necesarias para resolverlo.
\end{abstract}

Palabras clave: Úlcera crónica; Costo; Epidemiología; Salud pública; Tratamiento.

\section{Abstract}

Background: Chronic lower limb ulcers (CLLU) have an important burden to the individual and the healthcare system Objective: To determinate the number and cost of consultation and hospitalization associated to CLLU in a public hospital in Tucumán, Argentina.

Methods: Retrospective observational study. Cost estimation were calculated based on days of stay, treatments and laboratory tests in a inpatient population and the number of consultations, treatments and laboratory tests in a outpatient population.

Results: In 2013 and 2014, the overall number of consultation with ICD-10 codes was 7224 and the number of inpatient was 359.

The length of stay was 22.88 days. There was a mean of 0.41 surgeries per patient where $25 \%$ were amputations. The mean annual cost in a single public hospital was US\$ 4053.65 per inpatient and US\$ 3589.24 per outpatient. Conclusion: CLLU generate a great economic burden for the public Health System in Argentina. Therefore, there is a need of changing the way of registration of CLLU in hospitals, allowing the public Health System to become aware of the problem and generate the necessary policies to solve it.

Keywords: Chronic wound; Cost; Epidemiology; Public health; Treatment.

Introduction

Chronic lower limb ulcers (CLLU) remain a challenging problem in modern society, and represent significant medical, economic and social burdens $[1,2]$. The epidemiological rates vary considerably depending on diagnosis, year and country [3]. Chronic ulcers will continue to be a growing concern as increases life expectancy and more people will be at risk for developing these conditions [4] given the increasing prevalence of diabetes and other chronic diseases that may affect wound healing [5].

Successful treatment that stimulates healing is an 
essential step toward eliminating morbidity, improving quality of life for patients, and decreasing healthcare costs [6]. Surgical treatment accounts for the major portion of treatment activity [7]. The standard of care for chronic ulcers are debridement [8], infection control, moisture balance $[9,10]$ and wound cleansing, with pressure offloading for diabetic foot ulcers (DFU) [8] and pressure ulcers (PU) [4] and compression therapy for venous ulcers (VU) [9]. The combination of the high prevalence of chronic ulcers with the resource intensity of treatment, results in a high economic burden to the health-care system [4].

Data on treatment cost for CLLU are inconsistent and vary largely depending on disease, health system and evaluation method [11]. More precisely, in developed countries reported annual costs per patient for VU range from US\$ 4000 to US\$ 35000 [11]. Pressure ulcers have been observed to result in US\$ 700 to US\$ 90000 excess hospital cost and DFU has ranged from US\$ 11710 to US\$ 21400 in the first year [12]. Limited evidence is available on the costs of CLLU in Latin American countries. One study in Brazil with DFU showed an estimated average cost for outpatient management that range from US\$ 400 to US\$ 1600 [13] and the average hospitalization cost per patient range from US\$ 400 to US\$ 2700 [13]. Meanwhile, in Peru the annual cost per patient hospitalization range from US\$1022 to US\$ 7360 according to the treatment applied [14]. Major cost drivers were hospitalization, nursing costs and dressing material for health system [15] and topical drugs and medical products for patients [15]. In Argentina, there is a lack of information about epidemiological and economic impact of CLLU. Burden information is important for public health policy makers to advocate for implementation of prevention, treatment recommendations [13] and therapeutic effectiveness. Therefore, this study was undertaken to analyze the demographic and hospital economic characteristics of chronic lower limb ulcers in a public hospital in Argentina.

\section{Methods}

\section{A. Study population and data assessment}

A retrospective study of outpatients and inpatients treated at Angel C. Padilla Hospital during the period from January 1, 2013 to December 31, 2014 was performed. This is a referral hospital in Province of Tucuman and the northwest of Argentina. The examined population comprised all hospital consultations and admissions, based on the International Classification of Diseases (ICD-10): L97 (Ulcer of lower limb, not elsewhere classified), E11.5 (Type 2 diabetes mellitus with peripheral circulatory complications), I83.0 (Varicose veins of lower extremities with ulcer), I77.8 (Other specified disorders of arteries and arterioles) and L89 (Decubitus ulcer and pressure area).

Demographic information (age and gender) were collected from the patients' medical records over the study period. To estimate the cost of hospitalization the length of stay for inpatient and the number of consultations for outpatient were obtained. There were also identified treatments performed to the ulcer and to the control of infection, surgical procedures and laboratory tests.

\section{B. Calculation of cost}

The associated costs were calculated using the Nomenclator of Health Benefits for the Public Hospitals (NHM National Health Ministry Resolution No. 60-2015) and converted to 2014 US dollars. The estimated cost of CLLU inpatients includes total hospitalization days (medical and nursing fees, drug treatment, disposables and practice fees), laboratory tests and surgical procedures (amputation, surgical debridement, skin biopsies, bone biopsies, vascular surgery and skin graft). Outpatient costs include the total number of consultations, nursing fees and disposables for cleansing the ulcer and laboratory tests.

\section{Statistical analysis}

Data have been summarized and reported as percentage and frequency tables. All analyses were performed using SPSS (Statistical Package for Social Science) software (version 22.0) (SPSS Inc., Chicago, IL).

\section{Ethical standards}

This study was conducted with the approval of the Ethics and Teaching Committee from the Angel C. Padilla Hospital.

\section{Results}

\section{A. Consultations and outpatients characteristic}

The overall number of consultation with ICD-10 codes showing in Table 1 in the period of study was 7224, corresponding to 640 patients. The highest ratio of consultation occurred between 50 and 59 years old (55.46\%) with almost $97 \%$ of consultation recorded as L97. The mean age $( \pm \mathrm{SD})$ for male outpatient consultations was 59.53 $( \pm 13.06)$ years and $59.04( \pm 10.93)$ years for female outpatient consultations. The oldest patient was 88 years and the youngest was 16 years. A slight male predominance was observed in consultations (53.16\%). 
Table 1: "Age and gender distribution according to ICD-10 codification for consultation and hospitalization".

\begin{tabular}{|c|c|c|c|c|}
\hline & \multicolumn{4}{|c|}{ Consultation (n= 7224) } \\
\hline & \multicolumn{3}{|c|}{ Male } & \multicolumn{2}{c|}{ Female } \\
\hline $\begin{array}{c}\text { ICD-10 } \\
\text { Codes }\end{array}$ & $(\%)$ & Age $^{\mathrm{a}}$ & $(\%)$ & Age $^{\mathrm{a}}$ \\
\hline L97 & 51.83 & $\begin{array}{c}(19-88) \\
59.6 \pm 12.9\end{array}$ & 44.85 & $\begin{array}{c}(16-85) \\
58.9 \pm 11\end{array}$ \\
\hline L89 & 1.00 & $\begin{array}{c}(34-60) \\
49.7 \pm 13.8\end{array}$ & 0.33 & $\begin{array}{c}(73-76) \\
75.4 \pm 1.3\end{array}$ \\
\hline I83.0 & 0.00 & 0 & 1.33 & $\begin{array}{c}(43-68) \\
58.8 \pm 10.9\end{array}$ \\
\hline I77.8 & 0.33 & $\begin{array}{c}(78-80) \\
80 \pm 2.3\end{array}$ & 0.33 & $\begin{array}{c}(54-63) \\
59.7 \pm 3.7\end{array}$ \\
\hline E11.5 & 0.00 & 0 & 0.00 & 0 \\
\hline
\end{tabular}

\begin{tabular}{|c|c|c|c|c|}
\hline & \multicolumn{3}{|c|}{ Hospitalization (n=359) } \\
\hline & \multicolumn{3}{|c|}{ Male } & \multicolumn{2}{c|}{ Female } \\
\hline $\begin{array}{c}\text { ICD-10 } \\
\text { Codes }\end{array}$ & $(\%)$ & Age $^{\mathrm{a}}$ & $(\%)$ & Age $^{\mathrm{a}}$ \\
\hline L97 & 8.52 & $\begin{array}{c}(16-96) \\
54 \pm 18.7\end{array}$ & 6.04 & $\begin{array}{c}(17-80) \\
52.6 \pm 17.1\end{array}$ \\
\hline L89 & 0.27 & 36 & 0.00 & 0 \\
\hline I83.0 & 17.86 & $\begin{array}{c}(15-92) \\
45.1 \pm 19.7\end{array}$ & 6.87 & $\begin{array}{c}(20-86) \\
48.3 \pm 17.9\end{array}$ \\
\hline I77.8 & 0.82 & $\begin{array}{c}(44-76) \\
59.3 \pm 16.0\end{array}$ & 1.10 & $\begin{array}{c}(20-59) \\
45.3 \pm 18.2\end{array}$ \\
\hline E11.5 & 43.68 & $\begin{array}{c}(30-86) \\
58.3 \pm 9.9\end{array}$ & 14.84 & $\begin{array}{c}(33-93) \\
58.7 \pm 13.2\end{array}$ \\
\hline
\end{tabular}

a- Age is represented in (range) and mean $\pm \mathrm{SD}$

Twice a week outpatients assisted to the hospital to have wound cleansing with saline solution. A total of 65016 cleansings were registered in this study. Other treatments showing in Table 2 were performed on outpatients with CLLU. Topical medication was applied in $48.6 \%$ of the treatments. The most common were autolytic debridement products (chloramphenicol-collagenase ointment), antiseptics (molasses, silver sulfadiazine cream, Dakin's solution, ethanol, acetic acid and povidone iodine), moist occlusive dressing (soft dressing and transdermal patches) and pro-healing (skin graft, platelet-rich plasma and Centella asiatica). Two clinical laboratory tests (complete blood count, erythrocyte sedimentation rate, blood glucose test, blood urea nitrogen, creatinine blood test and urinalysis) were requested per year to each outpatient. A number of 1204 clinical laboratory tests and 602 bacterial identifications by culturing from biopsies samples (antibiotic sensitivity and Gram stain) were performed.

\section{B. Hospital admissions and inpatients characteristics}

During the 2-years study period, 359 inpatients were admitted in the Padilla Hospital and recorded using ICD-10 codes showing in Table 1. On the subject of the number of hospitalizations, $91.36 \%$ of inpatients were hospitalized once, while $7.52 \%$ were hospitalized twice, followed by $0.84 \%$ with three hospitalizations and $0.28 \%$ hospitalized four times. The sum of hospitalization days was 8214 . The average length of stay was 22.88 days and $71.0 \%$ stayed hospitalized more than 10 days (Figure 1). On the other hand, $42.0 \%$ of patients were hospitalized previous to the study period.

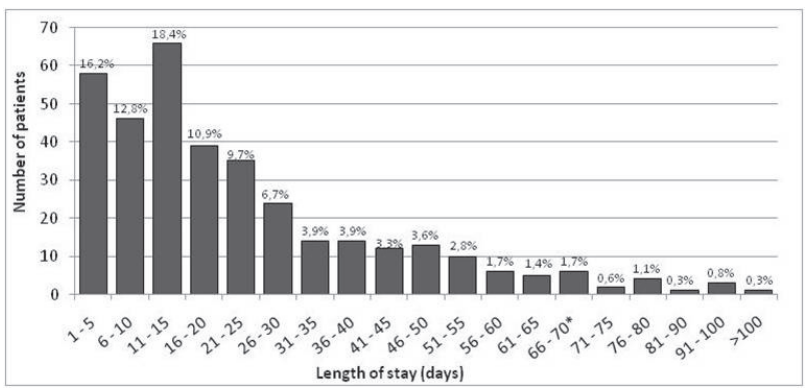

Figure 1: Length of stay. Distribution in an inpatient population with CLLU.

There was a considerable male predominance $(71.15 \%)$ among CLLU inpatients. The oldest patient was 96 years and the youngest was 16 years. The mean age $( \pm \mathrm{SD})$ for females was $54.5( \pm 8.6)$ years and $63.9( \pm 10.4)$ years for males. The age range with the highest frequency of inpatients for women was $50-59$ years $(39.0 \%$ of female population), and $60-69$ years for men, (34.0\% of male population). The leading ICD-10 codes among CLLU inpatients were E11.5 (58.52\%), I83.0 (24.73\%) and L97 $(14.56 \%)$.

Treatments performed for the management of the ulcer are shown in table 2. Specific treatments for the ulcer and the infection were applied in $19.77 \%$ and $1.39 \%$ had vascular surgeries. A total of 147 surgical procedures were performed, with $25.20 \%$ amputations during the study (Table 3). There was $9.47 \%$ of inpatient with an amputation before this study. Each week a clinical laboratory test (complete blood count, erythrocyte sedimentation rate, blood glucose test, blood urea nitrogen, creatinine blood test and urinalysis) were performed per patient. For these patients, a total of 2347 clinical laboratory tests and 378 bacterial identifications by culturing (antibiotic sensitivity and Gram stain) were performed. 
Table 2: "Treatments prescribed to outpatients and inpatients for the ulcer and the infection".

\begin{tabular}{|l|c|}
\hline \multicolumn{1}{|c|}{ Consultation } & $(\%)$ \\
\hline Debridement & 18,2 \\
\hline Antiseptics & 16,8 \\
\hline Wet dressing Hospitalization & 10,3 \\
\hline Pro-healing & 6,1 \\
\hline Anti-inflammatory & 4,8 \\
\hline \multicolumn{1}{|c|}{ (1) } \\
\hline Specific treatment for the ulcer & $(\%)$ \\
\hline Daily cure with saline solution & 58,5 \\
\hline Hydrocolloid dressing & 2,8 \\
\hline VAC therapy & 8,6 \\
\hline Growth factor therapy & 2,9 \\
\hline Lactobacillus ${ }^{\text {a }}$ & 1,4 \\
\hline Compression bandages & 2,9 \\
\hline Drains & 7,1 \\
\hline Treatment for infection & \\
\hline Molasses & 7,2 \\
\hline Alcohol + lidocaine & 4,3 \\
\hline Povidone-iodine & 2,9 \\
\hline & 1,4 \\
\hline
\end{tabular}

a- Lactobacillus refers to a topical treatment with Lactobacillus plantarum culture [16] promoting the chronicity of inflammation and wounds.

Because antibiotics fail to eradicate bacteria, especially in biofilm form, new therapeutic modalities may be required. In the present study, the effectiveness of bacteriotherapy with Lactobacillus plantarum on infected chronic venous ulcers was investigated and its effects on interleukin (IL

Table 3: "Amputation and other surgical procedures performed during hospitalization".

\begin{tabular}{|c|c|}
\hline Amputation $(n=37)$ & (\%) \\
\hline Minor amputation ${ }^{a}$ & $73.53 \%$ \\
\hline Trans-femoral amputation & $8.82 \%$ \\
\hline Syme's amputation & $2.94 \%$ \\
\hline Trans-tibial amputation & $2.94 \%$ \\
\hline Hallux amputation & $5.88 \%$ \\
\hline Trans-metatarsal & $5.88 \%$ \\
\hline Other surgical procedure & (\%) \\
\hline Surgical debridement & $66.67 \%$ \\
\hline Skin biopsy & $5.44 \%$ \\
\hline Bone biopsy & $1.36 \%$ \\
\hline Skin graft & $1.36 \%$ \\
\hline
\end{tabular}

a "Minor amputation" refers to amputation of toes

\section{Hospital cost}

Table 4 shows the estimated costs for CLLU hospitalizations and consultations. The mean cost to a single public Hospital per year was US\$ 4053.65 per inpatient and US\$ 3589.24 per outpatient. Hospital stay (medical and nursing fees, drug treatment, disposables and practice fees) were the main cost factor. The inpatients incurred relevant costs through the self-purchase of topical drugs and medical products (e.g. antibiotics). The majority of the inpatients were Medicare beneficiaries (67.69\%) with healthcare coverage. The main cost factor for outpatients was the nursing fees for wound cleansing using saline solution and sterile gauze.
Table 4: "Estimated cost of chronic lower limb ulcer hospitalization and consultation in 2013-2014"

\begin{tabular}{|c|c|}
\hline Outpatient & US\$ \\
\hline Consultation & 334585.26 \\
\hline Ulcer cleaning $^{\text {Laboratory tests }}{ }^{\mathrm{a}}$ & 1581675.79 \\
\hline Total hospital cost & 244461.29 \\
\hline Average cost per outpatient/year & 2160722.34 \\
\hline Inpatient & 3589.24 \\
\hline Hospital stay & 2472846.32 \\
\hline Amputation & 93648.42 \\
\hline Other surgical procedures & 132090.53 \\
\hline Laboratory tests & 252471.35 \\
\hline Total hospital cost & 2951056.61 \\
\hline Average cost per inpatient/year & 4053.65 \\
\hline
\end{tabular}

a- Laboratory test" includes clinical laboratory tests

and bacterial identification by culturing.

b- Other surgical procedures" includes surgical debridement, skin

biopsies, bone biopsies, vascular surgery and skin graft.

\section{Discusion}

The management of chronic wounds is complex, timeconsuming, and requires high level of resources [3], and can result in an important economic and public health burden, especially in low and middle income countries [13]. In Argentina healthcare is provided by both public and private sectors. Public healthcare service offers free of charge, and universal access to all the population. Despite the significant health and economic burden [17-20], there are not previous studies about epidemiological information and economic impact of chronic wounds in Argentina. This study was undertaken to analyze the demographic and hospital economic characteristics of chronic lower limb ulcers in a public hospital in Argentina.

The most frequent age range of ulceration in this study was between 50 and 59 years. This finding agreed with a nationwide study in Germany using ICD-10 codes for leg ulcers in outpatients and inpatients populations showing that the probability of developing a wound doubled between the ages of 50 and 60 years [3].

The use of ICD-10 codes allowed us to obtain results with standardized international coding criteria. However, the identification of patients based on the clinical diagnosis and subsequent coding could lead to an underestimation of cases because in our community physicians are not used to ICD-10 codes. Besides in some cases, patients were coded by the underlying disease and not by the ulcer-related code. Also, in the first consultation the codification is performed by the hospital's administrative staff. We found a very clear difference in classification distribution between outpatients and inpatients. In the outpatient population, 97\% were classified as L97, while only $14.56 \%$ of the inpatients received the same classification. This clearly shows that only when the patients are hospitalized they receive an accurate codification. The lack of accurate classification (and maybe of diagnosis) during consultations could be consider as a negative marker explaining the lack of healing effectiveness in this study population. 
On the other hand, most of inpatients were E11.5 $(58.52 \%)$. This result is influenced by the internal organization of the Province Health System (SIPROSA) that derives mainly diabetic patients to this hospital. This also could explain the high male predominance in inpatients (Table 1). Male gender predominance is consistent with many earlier studies [21], [22], [23]. Also, it is possible to suggest that males are more liable to foot trauma and hence they are commoner in diabetic foot ulceration [23].

This study shows major cost associated to wound cleansing. This burden could be underestimating considering that usually patients performed daily home cleansing of the wound or in Primary Health Care Centers, leading to an underregistration of the procedure.

During this study we observed different markers that are directly related with the lack of therapeutic effectiveness of the applied treatments affecting significantly the hospital cost of CLLU. For example, $8.64 \%$ of patients were hospitalized more than once during 2013 and 2014, and $42.0 \%$ were hospitalized previous to this study. A second marker was that $71 \%$ of patients stayed hospitalized more than 10 days due to CLLU complications with an average of 22 days compared to Germany and UK where the mean length of stay was 8.4 days and 12.8 days [11], [14]. Surgical procedures were the third marker. A mean of 0.41 surgeries were performed for each patient, and $25 \%$ of these procedures were amputations. Besides, $10.33 \%$ of patients were amputated during the study and $9.47 \%$ previous to this study showing a long medical history with low therapeutic effectiveness. Finally, only $19.77 \%$ of inpatients received specific treatments for the ulcer, including pro-healing treatments and treatments for infection which could also explain the lack of therapeutic effectiveness comparing to previous studies that focus on specific management of the ulcer [11], [21], [24], [25]. Another hypothesis to this low therapeutic effectiveness is the outpatient ICD-10 code misregistration leading to the use of unspecific or inaccurate treatments protocols for the CLLU healing. The problem of non-healing highlights the importance of effective diagnosis/codification and appropriate treatment [20]. Drew et al. suggest that ensuring effective and timely diagnosis and appropriate treatment is significantly more likely to affect costs [20].

Data on treatment costs for leg ulcers are inconsistent and vary largely depending on disease, health system and evaluation method [7]. For example, in developed countries as US and Germany health system spent annually an average annual cost per patient of US\$ 3846.15 and US\$ 11130, respectively [6], [11]. However, in developing countries as Brazil and Peru, DFU costs range from US\$ 400 to US\$ 2700 and US\$ 1022 to US\$ 7360, respectively $[13,14]$. Our results are consistent to the US costs with an annual average cost of US\$ 3589.24 per outpatient and US\$ 4053.65 per inpatient (Table 4).

In several developed countries the estimated costs are based on the full healing of the ulcer [20] and the type of ulcer [4], [14], [21], [26], [27] meanwhile in our study the results shows the annual cost for the management of CLLU. Therefore, we assumed that the healing cost will be higher; this shows the paradox of poverty/excess of expenditure that typically face the health systems of developing countries [28], [29], [30]. A major cause is the lack of information in developing countries about the economic burden of CLLU and the lack of evaluation of therapeutic effectiveness that allow optimizing treatments and reducing healing time.

This study had several limitations. Data were obtained from a single hospital. The use of diagnosis codes to identify individuals in our population may not be completely accurate. Individuals may have been misdiagnosed, with some individuals with chronic ulcers coded with a different diagnosis and other individuals without chronic ulcers unintentionally diagnosed as a having an ulcer. In this study, some medical records, classified as CLLU with ICD-10 codification, did not have data on ulcers, therefore information containing in those medical records were eliminated from the analysis. One hypothesis about the misdiagnosis records is that, in 2013 the medical records registration was performed by administrative personnel, not by the medical personnel. In addition the electronic registration system using ICD-10 coding was applied for the first time in 2012, and this could be one of the causes of misregistration. Another limitation could be the prevalence of wound type considering that, in recent years, Padilla Hospital has become in a center for DFU treatment.

\section{Conclusion}

The costs for the management of chronic wounds in a single public hospital in Argentina amounted to US\$ 2951,056.61 in the 2013-2014 period, generating a high economic impact on the public Health System. These costs were mainly associated with wound evolution times, hospitalization times, amputations and ineffective treatments. The results of this study have great implications in the management of public hospitals for the implementation of more efficient data records and adequate follow-up of the patient. Treatment of chronic wounds is time consuming, difficult, and the pathogenesis complicated. The management of chronic wounds in developed and developing countries faces enormous challenges. In this study, despite the underregistration we observed a high cost for the management of outpatient and inpatient CLLU in a single public hospital in Tucumán. Medical records showed an alarming underregistration of CLLU because professionals do not focus on the ulcer healing, but on the treatment of the underlying pathology. This decreases the probability of an accurate calculation of costs and therapeutic effectiveness leading to a vicious circle that involves, underregistration of poor therapeutic effectiveness, maintenance of old 
therapeutic protocols, with consequent long healing times and associated costs. There is a need to change the form of CLLU registration so that physicians and nurses have a comprehensive assessment and consistent understanding of the wound, leading to the choice of appropriate treatment options for the patient and, for the public Health System to become aware of the problem and take the necessary policies to solve it.

\section{Conflict of interest}

All authors declare that they have no conflict of interest.

\section{Acknowledgements}

the authors would like to thank the Hospital Angel Padilla and the Agencia Nacional de Promoción Científica y Tecnológica.

\section{References}

1. Agale sv. Chronic Leg Ulcers: Epidemiology, Aetiopathogenesis, and Management. Hindawi Publ Corp 2013;2013:9. doi:http://dx.doi. org/10.1155/2013/413604.

2. Franks PJ, Moffatt CJ, Doherty DC, Smithdale R, Martin R. Longer-term changes in quality of life in chronic leg ulceration. Wound Repair Regen 2006;14:536-41. doi:10.1111/j.1743-6109.2006.00160.x.

3. Heyer K, Herberger K, Protz K, Glaeske G, Augustin M. Epidemiology of chronic wounds in Germany: Analysis of statutory health insurance data. Wound Repair Regen 2016;24:434-42. doi:10.1111/wrr.12387.

4. Chan B, Cadarette S, Wodchis W, Wong J, Mittmann N, Krahn M. Cost-of-illness studies in chronic ulcers: a systematic review. J Wound Care 2017;26:S4-14. doi:10.12968/ jowc.2017.26.Sup4.S4.

5. Han G, Ceilley R. Chronic Wound Healing: A Review of Current Management and Treatments. Adv Ther 2017;34:599-610. doi:10.1007/s12325-017-0478-y.

6. Brem H, Stojadinovic O, Diegelmann RF, Entero H, Lee B, Pastar I, et al. Molecular Markers in Patients with Chronic Wounds to Guide Surgical Debridement. Mol Med 2007;13:30-9. doi:10.2119/2006.

7. Finn Gottrup, M.D. DMS, The. A specialized wound-healing center concept: importance of a multidisciplinary department structure and surgical treatment facilities in the treatment of chronic wounds. Am J Surg 2004;187:38-43. doi:http://dx.doi. org/10.1155/2013/413604.

8. Orsted, H. L., Searles, G. E., Trowell, H., Shapera, L., MiIler, P., \& Rahman J. Best Practice Recommendations for the Prevention, Diagnosis and Treatment of Diabetic Foot Ulcers : Update 2006. Adv Skin Wound Care 2007;20:655-69. doi:10.1097/01.
ASW.0000284957.16567.3a.

9. Burrows $C$, Miller R, Townsend D, Bellefontaine R, Mackean $\mathrm{G}$, Orsted $\mathrm{HL}$, et al. Best Practice Recommendations for the Prevention and Treatment of Venous Leg Ulcers : Update 2006. Adv Skin Wound Care 2007:611-21. doi:10.1097/01.ASW.0000284937.32707.c4.

10. Woo KY, Botros M, Kuhnke J, Evans R, Alavi A. Best Practices for the Management of Foot Ulcers in People with Diabetes. Adv Skin Wound Care 2013;26:512-24. doi:10.1097/01.ASW.0000436385.24508.d5.

11. Augustin M, Brocatti LK, Rustenbach SJ, Schäfer I, Herberger к. Cost-of-illness of leg ulcers in the community. Int Wound J 2014;11:283-92. doi:10.1111/j.1742481X.2012.01089.X.

12. Chan BCF, Cadarette SM, Wodchis WP, Mittmann N, Krahn MD. Lifetime cost of chronic ulcers requiring hospitalization in Ontario, Canada: A population-based study. Wound Med 2018;20:21-34. doi:10.1016/j. wndm.2018.01.002.

13. Toscano C, Sugita T, Rosa M, Pedrosa H, Rosa R, Bahia L. Annual Direct Medical Costs of Diabetic Foot Disease in Brazil: A Cost of Illness Study. Int J Environ Res Public Health 2018;15:89. doi:10.3390/ijerph15010089.

14. Cardenas MK, Mirelman AJ, Galvin CJ, Lazo-Porras M, Pinto $\mathrm{M}$, Miranda JJ, et al. The cost of illness attributable to diabetic foot and cost-effectiveness of secondary prevention in Peru. BMC Health Serv Res 2015;15:483. doi:10.1186/s12913-015-1141-4.

15. Purwins $\mathrm{S}$, Herberger K, Debus ES, Rustenbach SJ, Pelzer P, Rabe $\mathrm{E}$, et al. Cost-of-illness of chronic leg ulcers in Germany. Int Wound J 2010;7:97-102. doi:10.1111/j.1742481X.2010.00660.x.

16. Peral MC, Rachid MM, Gobbato NM, Huaman Martinez MA, Valdez Jc. Interleukin-8 production by polymorphonuclear leukocytes from patients with chronic infected leg ulcers treated with Lactobacillus plantarum. Clin Microbiol Infect 2010;16:281-6. doi:10.1111/j.14690691.2009.02793.x.

17. Lal вк. Venous ulcers of the lower extremity: Definition, epidemiology, economic and social burdens. Semin Vasc Surg 2015;28:3-5. doi:10.1053/j.semvascsurg.2015.05.002.

18. Clarke P, Leal J, Kelman C, Smith M, Colagiuri S. Estimating the cost of complications of diabetes in Australia using administrative health-care data. Value Health n.d.;11:199-206. doi:10.1111/j.15244733.2007.00228.x.

19. Rezende KF, Ferraz MB, Malerbi DA, Melo NH, Nunes MP, Pedrosa $\mathrm{HC}$, et al. Predicted annual costs for inpatients with diabetes and foot ulcers in a developing country - A simulation of the current situation in Brazil. Diabet Med 2010;27:109-12. doi:10.1111/j.14645491.2009.02871.x.

20. Drew P, Posnett J, Rusling L. The cost of wound care for a local population in England. Int Wound J 2007;4:149- 
55. doi:10.1111/j.1742-481X.2007.00337.x.

21. Hopkins RB, Burke N, Harlock J, Jegathisawaran J, Goeree R. Economic burden of illness associated with diabetic foot ulcers in Canada. BMC Health Serv Res 2015;15:1-9. doi:10.1186/s12913-015-0687-5.

22. Kiziltan ME, Gunduz A, Kiziltan G, Akalin MA, Uzun N. Peripheral neuropathy in patients with diabetic foot ulcers: Clinical and nerve conduction study. J Neurol Sci 2007;258:75-9. doi:10.1016/j.jns.2007.02.028.

23. Hokkam EN. Assessment of risk factors in diabetic foot ulceration and their impact on the outcome of the disease. Prim Care Diabetes 2009;3:219-24. doi:10.1016/j.pcd.2009.08.009.

24. Phillips CJ, Humphreys I, Fletcher J, Harding $\mathrm{K}$, Chamberlain G, Macey S. Estimating the costs associated with the management of patients with chronic wounds using linked routine data. Int Wound J 2015:1-5. doi:10.1111/ iwj.12443.

25. Powers JG, Higham C, Broussard K, Phillips TJ. Wound healing and treating wounds. Chronic wound care and management. J Am Acad Dermatol 2016;74:607-25. doi:10.1016/j.jaad.2015.08.070.
26. Guest JF, Ayoub N, Mcllwraith T, Uchegbu I, Gerrish A, Weidlich D, et al. Health economic burden that wounds impose on the National Health Service in the UK. BMJ Open 2015;5:1-9. doi:10.1136/bmjopen-2015-009283.

27. Rice JB, Desai U, Cummings AKG, Birnbaum HG, Skornicki $M$, Parsons N. Burden of venous leg ulcers in the United States. J Med Econ 2014;17:347-56. doi:10.31 11/13696998.2014.903258.

28. Van Doorslaer E, O'Donnell O, Rannan-Eliya RP, Somanaathan A, Adhikari SR, Carg Cc, et al. Catastrophic payments for health care in Asia. Health Econ 2007;16:1159-84. doi:10.1002/hec.

29. Sachs JD. Achieving universal health coverage in lowincome settings. Lancet 2012;380:944-7. doi:10.1016/ S0140-6736(12)61149-0.

30. Thiel S Van, Leeuw FL. The Performance Paradox in the Public Sector. Public Perform Manag Rev 2002;25:267-81. doi:10.1080/15309576.2002.11643 661. 